\title{
Single Stage Extra Cardiac Conduit Total Cavopulmonary Connection in Atrial Situs Inversus and Levocardia
}

\author{
Shamsher Singh Lohchab1, Ishani Lohchab², Ashok Chahal', Naveen Malhotra ${ }^{3}$, \\ Kuldeep Laller 4 \\ ${ }^{1}$ Department of Cardiac Surgery, Pandit Bhagwat Dayal Sharma Post Graduate Institute of Medical Sciences, \\ Rohtak, India \\ ${ }^{2}$ Pandit Bhagwat Dayal Sharma Post Graduate Institute of Medical Sciences, Rohtak, India \\ ${ }^{3}$ Department of Anaesthesiology, Pandit Bhagwat Dayal Sharma Post Graduate Institute of Medical Sciences, \\ Rohtak, India \\ ${ }^{4}$ Department of Cardiology, Pandit Bhagwat Dayal Sharma Post Graduate Institute of Medical Sciences, Rohtak, \\ India \\ Email: sslohchab@hotmail.com
}

Received 8 April 2016; accepted 5 August 2016; published 8 August 2016

Copyright (C) 2016 by authors and Scientific Research Publishing Inc.

This work is licensed under the Creative Commons Attribution International License (CC BY).

http://creativecommons.org/licenses/by/4.0/

(c) (i) Open Access

\begin{abstract}
10-year female child was presented with complex congenital heart defect-atrial situs inversus, levocardia, discordant atrioventricular connections, double outlet right ventricle, ventricular septal defect, pulmonic stenosis and straddling of atrio-ventricular valves along with bilateral superior vena cava and large patent ductus arteriosus. We describe here the strategy adopted to perform single stage fenestrated extra cardiac conduit total cavo-pulmonary connections in this patient especially concerning cardiac malposition of atrial situs inversus and levocardia.
\end{abstract}

Keywords

Single Ventricle, Fontan Operation, Situs Inversus and Levocardia

\section{Introduction}

Extra cardiac conduit modification of Fontan procedure is currently becoming the preferred technique for palliation of single ventricle physiology [1]. The surgical technique is well described in normally positioned heart however there is paucity of literature of describing stepwise surgical strategy in different malpositions [2]. We 
report here the surgical strategy adopted for performing the fenestrated extra cardiac conduit total cavo-pulmonary connection (TCPC) in a patient of double outlet right ventricle (DORV), ventricular septal defect (VSD), pulmonic stenosis (PS), discordant atrioventricular connections, straddling of atrio-ventricular (A-V) valves and bilateral superior vena cava (SVC) having atrial situs inversus and levocardia

\section{Case Report}

10-year female child was presented with cyanosis since 6 months of age. Her body weight was $18 \mathrm{~kg}$, height 119 $\mathrm{cm}$ and body surface area $0.77 \mathrm{M}^{2}$. Haematocrit was 40 and Spo2 was $75 \%$. She had visceral situs inversus as depicted in X-ray Chest showing liver on left side and stomach bubble on right (Figure 1). Ultrasonography of abdominal organs showed normal liver and spleen but abnormally positioned on opposite side. She was diagnosed with complex congenital heart defect DORV, large VSD, PS, discordant atrioventricular connections, and straddling of AV valves along with left sided SVC and large patent ductus arteriosus (PDA) on transthoracic echocardiography. The anatomy of pulmonary artery was adequate, bilateral ventricular function normal and normal $\mathrm{A}-\mathrm{V}$ valves function. Cardiac catheterization was performed to determine the suitability of Fontan operation. She had normal dimensions of pulmonary arteries, mean pulmonary artery (PA) pressure of $12 \mathrm{~mm}$ of $\mathrm{Hg}$ and pulmonary vascular resistance was 2.4 woods units. As all essential criteria were suitable for Fontan operation hence was taken up for surgery. Informed consent of patient was taken for single stage extra cardiac conduit TCPC. Midsternotomy was done and after pericardiotomy the external anatomy of the heart was defined. Cardiac malposition was atrial situs inversus i.e. right atrium, SVC and inferior vena cava (IVC) being left sided and left atrium right sided and posterior along with levocardia as both ventricles were normally positioned along with additional right sided SVC (Figure 2). We thought out a well-planned safe surgical strategy to avoid any difficulty. As IVC was left sided and behind left ventricle so access was difficult on beating heart so it was not possible to avoid cardiopulmonary bypass (CPB). Standard steps of CPB and cardioplegic arrest were performed with following modifications. Cannulation low down on IVC was avoided and cannulation of right atrium (RA) on left side was done along with bilateral SVC cannulation. Dissection around IVC on diaphragm and cannulation of IVC was performed on CPB with arrested heart and then IVC was drained and at this stage RA cannula was used for venting beforehand left ventricle (LV) venting was done through cannula in right sided left atrial appendage (LAA). The procedure followed first division of PDA followed by transection of main pulmonary artery (PA) as usual. Transection of right SVC was done and anastomosis of SVC to right sided PA end to side was made with 7-0 polypropylene and the atrial end was oversewen with 4-0 polypropylene sutures. After that the anastomosis of left SVC to left sided PA and owersewen of atrial end was performed in similar fashion. As $18 \mathrm{~mm}$ graft planned for this patient seemed large one compared to left sided PA size hence $16 \mathrm{~mm}$ e PTFE graft

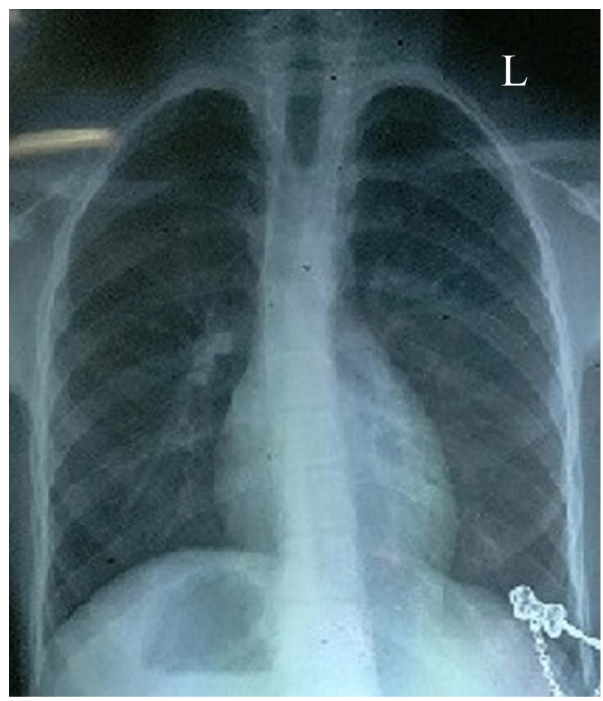

Figure 1. X-ray Chest showing levocardia with visceral situs inversus i.e. liver on left side and stomach bubble on right side. 


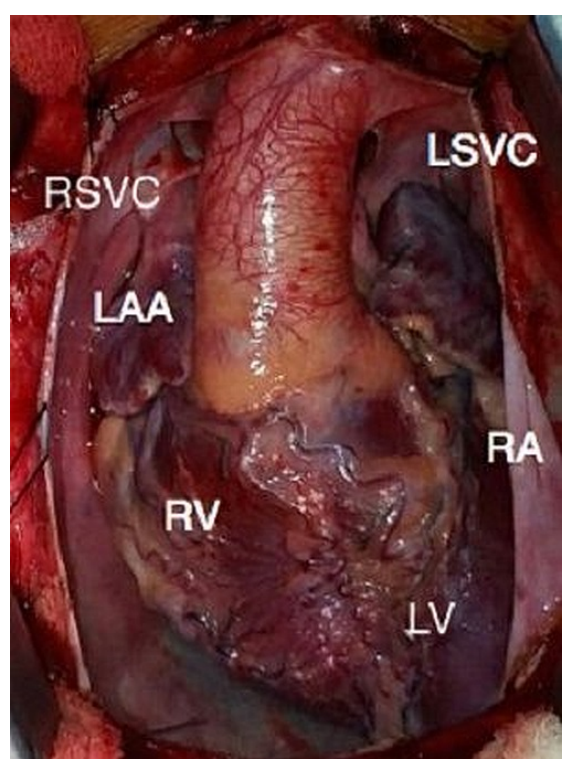

Figure 2. Intraoperative photograph demonstrating atrial situs inversus i.e. right atrium, SVC and inferior vena cava (IVC) being left sided and left atrium right sided and posterior along with levocardia as both ventricles were normally positioned along with additional right sided SVC.

was anastomosed between IVC and left sided PA with 6-0 polypropylene continuous sutures and the atrial end was oversewen with 4-0 polypropylene sutures. Fenestration was made between conduit and RA $4 \mathrm{~mm}$ size by punch and directly suturing the free wall of RA to conduit around the opening in conduit with 5-0 polypropylene continuous suture. All these operative steps are depicted in Figure 3 which was done on arrested heart by surgeon standing on right side of patient.

\section{Results}

CPB time was 250 minutes and Aortic cross clamp time was 128 minutes. The contributing factors making the procedure lengthy were the single stage on arrested heart due to cardiac malposition. She was weaned off from CPB on dopamine $5 \mu \mathrm{gm} / \mathrm{kg} /$ minute and milirinone $0.5 \mu \mathrm{gm} / \mathrm{kg} /$ minute and continued for 24 hrs postoperatively. She was kept on mechanical ventilation with usual settings to decrease pulmonary vascular resistance and was extubated after 12 hours. Oral sildenafil $2 \mathrm{mg} / \mathrm{kg} /$ day and aspirin $75 \mathrm{mg} /$ day were started on day 1 . Patient maintained normal hemodynamic parameters. No arrhythmias or pleural collections occurred. Chest tubes were removed on 4th post op day. Patient made uneventful recovery and discharged on 7th PO day with Spo2 of 89\% on room air. She has been followed up for 9 months and having usual normal recovery with Spo2 of 95\%.

\section{Discussion}

Biventricular repair is preferred in DORV, VSD and PS but it is not possible in this patient due to discordant atrioventricular connections, straddling of A-V valves and atrial situs inversus, hence Fontan operation is planned in this patient [3]-[5]. The modified Fontan operation using extra cardiac conduit is currently favoured in comparison to lateral tunnel total cavopulmonary connection due to decreased incidence of atrial arrhythmias and pleural collections and avoidance of CPB [6]. The surgical steps of this procedure are well described in normally positioned heart but there is no clear-cut defined strategy in different cardiac malpositions [7] [8]. So to perform this procedure in atrial situs inversus and levocardia required a well thought out plan as described in methods. Single stage TCPC was done in this patient as the diagnosis was made late as usual in third world countries [9]. Fenestration of conduit to right atrium was preferred in this patient although PVR was 2.4 woods units as fenestration helped to decrease the Fontan failure rate and pleural effusions [10]. 


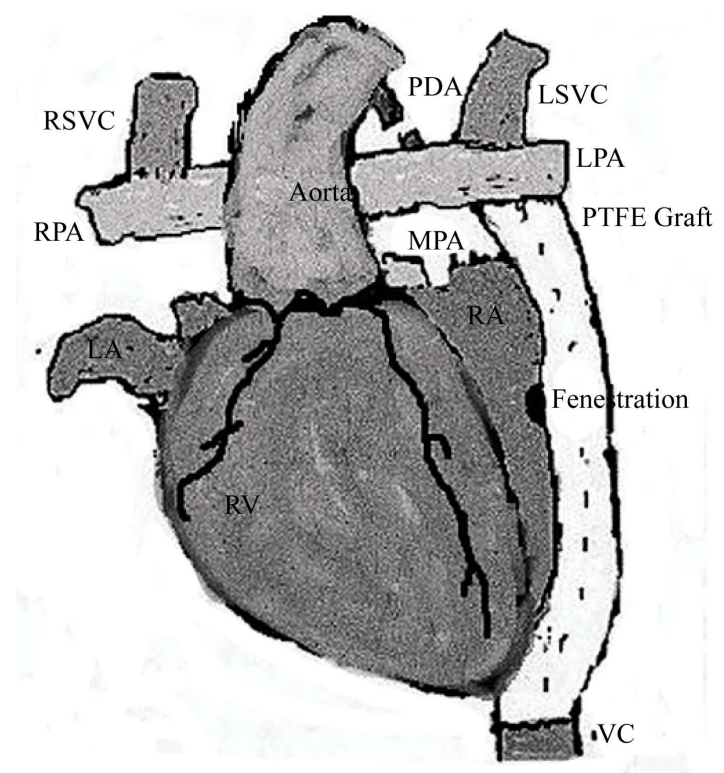

Figure 3. Artistic diagram showing the various operative steps of fenestrated extra cardiac TCPC.

\section{Conclusion}

Extra cardiac conduit TCPC in atrial situs inversus and levocardia can be safely performed with a well thought out strategy. The procedure without CPB may be very difficult and hence should be performed on arrested heart especially handling of left sided IVC behind LV in this malposition.

\section{Ethical Approval}

All procedures performed in studies involving human participants were in accordance with the ethical standards of the institutional and/or national research committee and with the 1964 Helsinki declaration and its later amendments or comparable ethical standards.

\section{Disclosures}

All authors declare that there is no conflict of interest in this article. The authors declare that the patient has given approval and consent to the publication of this article.

\section{References}

[1] Haas, G.S., Hess, H., Black, M., Onnasch, J., Mohr, F.W. and van Son, J.A.M. (2000) Extra Cardiac Conduit Fontan Procedure: Early and Intermediate Results. European Journal Cardio-Thoracic Surgery, 17, 648-654. http://dx.doi.org/10.1016/S1010-7940(00)00433-4

[2] Bradley, S.M. (2006) Extra Cardiac Conduit Fontan Procedure. Operative Techniques in Thoracic and Cardiovascular Surgery, 11, 123-140. http://dx.doi.org/10.1053/j.optechstcvs.2006.03.005

[3] Puga, J.F. (2000) The Role of the Fontan Procedure in the Surgical Treatment of Congenital Heart Malformations with Double-Outlet Right Ventricle. Seminars in Thoracic \& Cardiovascular Surgery: Pediatric Cardiac Surgery Annual, 3, 57-62. http://dx.doi.org/10.1053/tc.2000.6504

[4] Hsu, K.H., Chang, C.I., Huang, S.C., Chen, Y.S. and Chiu, I.S. (2016) 17-Year Experience in Surgical Management of Congenitally Corrected Transposition of the Great Arteries: A Single-Centre's Experience. European Journal CardioThoracic Surgery, 49, 522-527. http://dx.doi.org/10.1093/ejcts/ezv148

[5] Karl, T.R., Quintessenza, J. and Jacobs, J. (2016) Anatomic Repair for Congenitally Corrected Transposition: The Promise and the Reality. European Journal Cardio-Thoracic Surgery, 49, 528-529. http://dx.doi.org/10.1093/ejcts/ezv122

[6] Tokunaga, S., Kado, H., Imoto, Y., et al. (2002) Total Cavopulmonary Connection with an Extracardiac Conduit: Ex- 
perience with 100 Patients. The Annals of Thoracic Surgery, 73, 76-80. http://dx.doi.org/10.1016/S0003-4975(01)03302-1

[7] Morizumi, S., et al. (2012) Appropriate Route Selection for Extra Cardiac Total Cavopulmonary Connection in Apicocaval Juxtaposition. The Annals of Thoracic Surgery, 94, 179-184. http://dx.doi.org/10.1016/j.athoracsur.2012.03.026

[8] Hsu, K.-H., et al. (2011) Total Cavopulmonary Connection with Innovative Combined Lateral Tunnel and Extracardiac Conduit in Heterotaxy Syndrome. The Annals of Thoracic Surgery, 92, 1907-1908. http://dx.doi.org/10.1016/j.athoracsur.2011.05.028

[9] Cherian, K.M. (2004) Management of Complex Congenital Heart Disease: Indian Experience. Indian Journal of Thoracic and Cardiovascular Surgery, 20, 64-70. http://dx.doi.org/10.1007/s12055-004-0022-y

[10] Airan, B., Sharma, R., Choudhary, S.K., et al. (2000) Univentricular Repair: Is Routine Fenestration Justified? The Annals of Thoracic Surgery, 69, 1900-1906. http://dx.doi.org/10.1016/S0003-4975(00)01247-9

\section{Submit or recommend next manuscript to SCIRP and we will provide best service for you:}

Accepting pre-submission inquiries through Email, Facebook, LinkedIn, Twitter, etc. A wide selection of journals (inclusive of 9 subjects, more than 200 journals)

Providing 24-hour high-quality service

User-friendly online submission system

Fair and swift peer-review system

Efficient typesetting and proofreading procedure

Display of the result of downloads and visits, as well as the number of cited articles

Maximum dissemination of your research work

Submit your manuscript at: http://papersubmission.scirp.org/ 